\title{
13. EXTrAORdinary Stories, a Mariano Llinás Postmodern Art Film
}

\author{
Gabriela Rivadeneira Crespo
}

\begin{abstract}
By analyzing EXTRAORDINARY STORIES (HISTORIAS EXTRAORDINARIAS), a 2008 movie by Argentinean filmmaker Mariano Llinás, Gabriela Rivadeneira Crespo questions the "productivity of cinema devices" to fully exemplify the type of postmodern film where cinema and contemporary art collaborate. Paradoxically, this kind of film, given the radical choices that govern it, places it in an expanded film, but marginalizes it in relation to cinema industry. The locations and modes of reception of such films are also part of the definition of post-cinema in the post-art era.
\end{abstract}

Keywords: Device, postmodern, contemporary art

Our approach to the post-cinema subject will consider movies and their production process as a set of determinant decisions regarding its engagement or disengagement with the art field. We understand art-making as a self-conscious operation in a complex field, where different contradictory forces come into conflict. When artists build their work, they also problematize an idea of art that is mobilized by its form. This process constitutes the very condition for art to emerge, the occasion through which art can appear. From this perspective, a film can be considered a work of art if it is the result of an artistic investigation, that is to say, a reflection on the idea of cinema as an artistic medium, device, form and way of pushing art boundaries and definitions.

Although cinematic films are generally considered part of the "seventh art," we support the idea that art is not always present in films. It is true that since the invention of photographic film, cinema, television and video, a long history of audiovisual devices has been traced. In view of the existent multiplicity of uses for filmic objects (for the most diverse purposes, whether

Chateau, D., and J. Moure. Post-cinema: Cinema in the Post-art Era. Amsterdam: Amsterdam University Press, 2020 DOI 10.5117/9789463727235_CH13 
artistic, political, educational, advertising, industrial, propaganda, etc.) as part of our research, it seemed fundamental to dig in and differentiate within the films themselves, which makes them part of a contemporary way of thinking and making art in a postmodern era. We will propose certain examples of films, artists, and filmmakers that have placed art at the center of their explorations, focalizing the idea of art and the artistic universe as their horizon of work.

Therefore, more than looking into new ways of making films, the analysis will focus on specific artistic research behind the filmmaking process. We would like to propose a film that is very likely to be unknown in Europe, as well as in most parts of the world, HISTORIAS EXTRAORDINARIAS (EXTRAORDINARY STORIES), a 2008 film by Mariano Llinás (Argentina). ${ }^{1}$ We think Llinás's movie is a postmodern work in the sense that it brings the productivity of cinematic devices into question; it also generates certain disorganization through the appropriation of generic forms (such as literature and other film genres), pointing to their validity and reflecting on their operability by deconstructing their forms, thus generating tensions and intensities.

\section{"I Think That the Film Looks Like Those Reckless Gamblers: It Is Born, It Enjoys and It Dies in Its Law" (Llinás and Koza 2009)}

EXTRAORDINARY STORIES is structured into three acts of 80 minutes each and a total of eighteen chapters to tell three alternating stories, and is usually projected with two ten-minute intervals. It tells the story of three characters named X (Mariano Llinás), Z (Walter Jakob), and H (Agustín Mendilaharzu), three ordinary men whose lives will be modified by different fortuitous events which, in turn, will generate new stories. The first character, X, kills a man after witnessing a violent event and decides to hide in a hotel. The second, $\mathrm{Z}$, begins to obsessively investigate the life of a man who has just died and whom he has replaced in his new job, while the third, $\mathrm{H}$, oversees a mission that he does not fully understand.

The protagonists are "non-characters"; they are mere conductors of the narrative, without psychologies, backgrounds or previous characteristics. This is assured by the decision to avoid naming the principal characters,

1 The film was first shown at the BAFICI (2008) and was projected at several other Film Festivals: Torino, Cinequest, Miami, Los Angeles, Vancouver, Nantes, and Wisconsin, and was released in New York in 2011. Historias EXTRAORDINARIAs (2008). Release Info. IMDb: https://www.imdb.com/title/tt1225831/releaseinfo?ref_=tt_dt_dt. Accessed May 9, 2019. 
instead identifying or differentiating them by means of a letter of the alphabet. The letters $\mathrm{X}, \mathrm{Z}$, and $\mathrm{H}$ emphasize the absence of needing to give them a personality, a psychological depth, becoming a signal of the characters' selflessness. Evacuating any specific trait of identity is an operation that places us, from the very beginning of the film, far from the aesthetic of expressing the old traditional self, or the modern subjectivity depth model. On the contrary, we are placed before multiple characters as image surfaces, over which a voice-over narrative is developed.

The first story begins in an unknown town in an Argentinean province with an unknown man called $\mathrm{X}$ by an unknown male voice-over. The only thing we are told about him is that he is travelling for a sort of "bureaucratic and gray work. Any work" (Film voice-over; my translation). Next, he is described in terms of what he is not: "he is not a journalist; he is not a detective, nor a writer, photographer or scientist; he is nothing that can arouse emotion or interest in advance. We may rather imagine him as a technician or a municipal inspector or a land surveyor" (Film voice-over; my translation). The second protagonist has a similar presentation:

A man who arrives in a town to take over someone's job. That man, our protagonist, we will call $\mathrm{Z}$. The only thing that we need to know about him is that it's his first time in a high-ranking position, his first time as a boss. The man who hired him tells him, "Don't worry. It's a quiet job, no decision-making, nothing new, you won't have any problems. It might be routine though, but you get used to it quickly. You should work there for a few months while you look for something better. But don't misjudge it either; the guy before you stayed there for twenty years. Be careful." That will never happen to me, $\mathrm{Z}$ says to himself, I am not like that. (Film voice-over; my translation)

The third main character is part of a nested story which may be considered a ramification of the second story. Through the same voice-over, we are introduced to the third man: "H receives a call from a strange man who hires him for a very strange job: to travel the river in search of forgotten monoliths, checking on their condition and taking their photographs. $\mathrm{H}$ doesn't fully understand these monoliths. The upset man who hired him says he doesn't understand them either: 'Just don't ask me questions and don't cause me more trouble.' One hour later, $\mathrm{H}$ is already in the river. His journey has begun" (Film voice-over; my translation).

The structure of the film is organized by the fragmentation and interlacing of the three main stories, as well as multiple other secondary nested stories. 
Fragmentation is also what defines the three main characters; they are a pure fragmentation of themselves. The voice-over presents an empirical description of $\mathrm{X}, \mathrm{H}$ and $\mathrm{Z}$, that operates as a decentering and deconstructive machine (we are in a totally opposite logic to that of the modern subject or psyche). We are confronted with three individuals, three average men, dissolved in an unclear contemporary organizational bureaucracy, in which old, strong emotions are replaced by surface intensities. One of the most enigmatic secondary characters is literally defined by a series of fragmented elements, by indexed surfaces: series of words, cryptic notes in a notebook, marked places in a countryside map, lists, postcards, various passports, money, books, etc. Others are built on the basis of newspapers, TV or radio news or police reports. It is as if most of the characters are cursed by impenetrable fragmented surfaces: columns, lines, traces, writings, clues, remains and impersonal floating intensities from which an uncertain past is recorded.

Therefore, the film is composed by a group of random inert objects and characters, with no link to an original vital world; they assure the manifestation of a general absence of depth, where the objective world itself is transformed into a set of simulated images. Llinás's universe uses any insignificant, neutral or ordinary character or element of daily life as potential material for the activation of fiction as a promise of an enigmatic mystery. The three omniscient narrators are the ones who carry out the narrative. The peculiarity of the procedure is that these voices are not there to explain what happens in the image, but to refute that tautology: they anticipate the story, cast it in doubt, contradict it, impregnate it with sense or suddenly take it away. An omnipresent storytelling where ingenuity, observation skills and a pataphysical interpretation of facts put together a larger system, a huge fiction machine that persistently disseminates stories of different calibers and sizes, which are intertwined with one another although they do not necessarily have points of contact. The three main stories are merely the trigger of a profusion of other stories. More than a road movie, EXTRAORDINARY STORIES is a long river movie, which will develop its current in an infinity of streams, secondary courses and even dry beds, which do not lead to anything.

The philosopher, Fredric Jameson, states that one of the functions of a work of art is to situate us in the world. Llinás's film situates us in a postmodern, cultural, imaginary world (fragmented, undetermined, intertextual, hybrid, parodical), as well as in a deconstructed view of the world (mistrust of truth categories and of grand narratives, doubt of filmic image, etc.). The different formal elements that constitute the film can be seen as interpretative vehicles designating a system of work to structure the film. 
To the already mentioned, the director's statements must be added, given that Llinás declares his commitment to a project related to art forms and art space. He explicitly places his movie in the art and cinema tradition in which he positions himself:

Initially, my intention was to build a film as close as possible to a novel, almost like a nineteenth-century adventure novel, with the voice-over as the guiding instrument. The intention was to explore the extent to which this was possible, in a discipline such as cinema in which the notion of classic narration had exploded more than half a century ago. How can that emotion and narrative vigor be re-situated today? How can one be sure of not making a film that is too self-conscious, satirical or absolutely nonsensical? The construction of the film was the progressive answer to these questions. (Llinás and Koza 2009; my translation)

Llinás developed the three central arguments based on three classic premises: a man who is accused of a crime he did not commit, a treasure map, and a bet. These structural elements of the intrigue, the predominance of the voice-over giving sense to mute and non-action film footage and photographic images, but also Llinás's declaration of his intention to build a film like a novel, as well as all the references to film genres made through the film's image and soundtrack (road movie, river movie, thriller, comedy, melodrama, false documentary, adventure film, local costumbrismo, war film, etc.), place his movie explicitly in the field of art. As Fredric Jameson affirms, generic concepts have a strategic value that lies clearly in their function, which makes it possible to coordinate "an immanent formal analysis of the individual text with a double perspective: the history of forms and the evolution of social life" (Jameson 1983, 92).

Jameson asserts that a generic concept basically operates as a reception category, allowing for the anchorage of work in the world and for its placement inside a historical perspective (of both social life and artistic forms). The genres are classificatory artistic notions and, according to Jean-Marie Schaeffer, they serve less to label than to provide references, less to classify than to interpret. Additionally, Schaeffer says that the genres are operative notions and, almost exclusively, artistic (Schaeffer 1989). As Jameson says, through the use of generic forms, artistic works are proposed as social contracts; they have the function to lead the eye and offer a reading frame:

Genres are essentially literary institutions, or social contracts between a writer and a specific public, whose function is to specify the proper use of 
a particular cultural artifact. The speech acts of daily life are themselves marked with indications and signals (intonation, gesturality, contextual deictics and pragmatics), which ensure their appropriate reception.(1983, 92-93).

The artistic genres therefore function as a form of mediation between art and the public, which not only place the work in a precise aesthetic and social history but also serve to provide benchmarks, self-regulating perceptual signals that will ensure and condition our perception and our experience of the work. In other words, they are frames of interpretation previously adopted or reinvented by the artist during the process of creation, but which the spectator also adopts during the reception process of the work.

\section{The Reasons of the Strongest}

From a cultural, industrial and market point of view, HISTORIAS EXTRAORDINARIAS is a marginal film. This condition is determined by several reasons that we could describe as immanent to the film. We could start by mentioning its 245-minute length. Its projection duration challenges the conventional or preformatted film circulation logic and cinema exploitation structures (that materialize in a series of reception devices involving programming, schedules, box office, cinemas, etc.). We could affirm, without the fear of being wrong, that the main reason for its invisibility is its duration. In today's cinema culture, it is simply not profitable; a cinema culture that historically has been a battlefield for filmmakers, researchers and artists. It might be illustrative to recall Eisenstein's critical position on the new possibilities offered to the cinema during his lecture given on September 17 , 1930 in Hollywood, before the Congress of Technicians of the Academy of Cinematographic Art and Science. The conference attendees were invited to discuss the new proportions that the big screen had to adopt $(3 \times 4.3$ or $3 \times 5$ or $3 \times 6$ ) and defended formats with arguments centered on the sovereignty of an aesthetic tradition (an alleged predominance of horizontal frames in visual arts), physiological characteristics (the configuration of the eye and its muscles), and commercial reasons (standardization would reduce costs).

On this occasion, Eisenstein strove to dismantle each of these arguments while highlighting the artistic potential of cinema as a new form of art entirely to be explored - an art, he says, based on the phenomena of dynamics and speed, with a possibility of an intrinsic existence to itself, whose lasting quality is independent of the shown schedules (as in theater, music 
or dance), and for whom all formatting undermines future experiments and creative research on cinema. Eisenstein supported the figurative potential of the screen format, seeing the possibility of questioning or reformulating all the aesthetics of the spatial composition of cinema. He lamented that for 30 years the experimentation was rendered futile precisely because of the standardization of the proportions of the frame of the screen. He also pointed out the enslavement of the mind to routine, traditionalism, and commercial pressure that seek to limit cinematographic devices to the exclusion of all artistic research (especially at the level of vertical compositions). On the contrary, Eisenstein proposed that the cinema screen be dynamic, of variable dimensions, and able to show with absolute magnificence any geometrically conceivable shape of the image, as well as all the tensions that the camera finds in reality (Eisenstein 1988, 206-218).

What is particularly important and interesting about Eisenstein's position is that in his lecture, he does not simply expose a personal opinion, but instead, analyzes the state of things: he analyzes the watchwords that engage the cinematographic practice in stagnation, making its artistic development rather difficult. Eisenstein not only makes a denunciation or an inventory but takes the floor to make a real proposal; he brings with him a project; he opens up a possibility, a way to question and change the cinematographic world as it was. Eisenstein thus contributes to a reflection on the technical possibilities still unexplored and yet already domesticated by "the reasons of the strongest" (Jean-Luc Godard, in CHAmbre 666, a Wim Wenders film, 1982).

It is compelling to notice today that upon questioning the artisticness of cinema, it immediately creates a certain level of tension. One can probably attribute this to the fact that the struggle for recognizing cinema as a seventh art has been long and "bloody," or rather that it is quite recent, or even the fact that this recognition still is not well stabilized. However, when one questions the artistic nature of television, then one feels much more at liberty and does not have to fear violent reactions; on the contrary, one could even envisage a certain unanimity. Yet, both are techniques which are primarily dependent on a market for the production of images and sounds, and powers in accordance with interests and logics quite far from those of art. Both techniques have been explored and authenticated as artistic means. Again, it can be said that television has, at least in part, conquered a market that was hitherto occupied by cinema, adding a characteristic of its own which is remote, live and simultaneously broadcasted.

In the industrial context, the worlds of both cinema and television can be defined as a sort of organization and set of activities and services that 
exploit a technical process and ensure the development, marketing and dissemination of audiovisual products resulting from said technical process. In principle, this industrial context is facing an imbalance and conflict with the different guiding forces that drive the artistic context. It seems to us that this tension is particularly visible and heightened in certain contexts where art mixes with industrial reproduction and diffusion techniques (music, literature, radio, television, etc.) and, in particular, as far as our research is concerned, with filmmaking. Above, we have seen the case of Eisenstein and the tension which has existed for a long time between the artistic interests which sought to explore the potential powers of techniques, on the one hand, and the economic powers which sought to freeze and standardize technical devices in order to save costs and achieve greater profitability, on the other.

However, the struggle of interest that we report here is not precisely for an economic capital unequally distributed within the cinema or TV since the artistic struggle does not target the egalitarian sharing of said profitability. The artistic struggle is centered on the redefinition of what is held as art, of what is likely to have an artistic value. The tension is thus placed at the heart of the interests peculiar to each position, in the conflicting encounter between the position of the artistic agents and that of the economic agents. The Letterists have clearly noted the conflict between these two principles and have made it very clear in the Letterist International: "USEFUL TO REMEMBER. Everything that maintains something contributes to the work of the police. Because we know that all ideas or behaviors that already exist are insufficient. Today's society is divided only into Letterists and Indicators" (Dahou et al. [1953] 1996, 12).

If we want to talk about the audiovisual field and, specifically, cinema as a technique of art or as a territory for artistic creation, we must take into account that the artistic struggle has never been partisan of the management of definitions or the perpetuation of identifications (maintained by a minority in a power position). If there is something in common within the artistic work - of any art made by means of any technique or medium - it is the search for the exception to established rules; art has always been a form of dissent, a perpetual self-redefinition and creation of the new. Moreover, Jean-Luc Godard also had identified the conflict between these two different principles, and he situates the problem not exactly within a specific field but in a more general structure that crosses all domains: in culture. Godard argues that there is the rule and there is the exception: "There is the culture that is the rule, which is part of the rule. There is the exception, which is art, which is part of art. [...] and it is the rule that wants the death of the exception" (Godard 1996, 14, 18). In this sense, to be able 
to make art, we will definitively need to dissociate any work procedure from cultural expectations. This point of view clearly goes against more widespread positions that draw little distinction between art and culture or the cinema industry, positions that align their arguments with the value of the "cultural use" of devices, whose validation is achieved by measuring the dominant uses in cultural history.

As previously mentioned, EXTRAORDINARY STORIES is 245 minutes long and is usually projected with two ten-minute intervals. It is Llinás's second film; the first, BALNEARIOS (2002, $80 \mathrm{~min}$.), is a documentary (as well as a mockumentary) about beach resorts and bath stations in Argentina. His third film, LA FLOR (2018, $814 \mathrm{~min})$, took him almost ten years to complete. It is important to mention that if EXTRAORDINARY STORIES has difficulties in terms of being projected or accepted nowadays, in regular programming at standard commercial movie theaters, LA FLOR geometrically multiplies this same difficulty due to its duration of almost fourteen hours.

For EXTRAORDINARY STORIES, Llinás worked with a limited production team, that is, four people - in addition to the actors - sometimes reaching a number of ten, whose roles were interchangeable. Hence, according to the needs, the director, the actors and the technical team may exchange roles and be production-, props-, makeup- or catering assistants as well. For instance, the three omniscient voice-overs are done by Llinás's close friends and older sister (Daniel Hendler, Juan Minujín, and Verónica Llinás). ExTRAORDINARY STORIES cost around 40,000 USD for the entire production. ${ }^{2}$ Llinás has repeatedly declared his commitment to a research process aimed at renewing the collective field of cinematographic art and points out the obsolescence of certain legitimated ideas about cinema:

The issue with regard to the INCAA (Argentinean National Institute of Cinema and Audiovisual Arts) is that it only thinks about cinema from an industrial perspective, while I and those who work with me, consider it from an artisan's point of view. It's simple: we want to show that cinema can be an activity that is as accessible as any other artistic discipline, to the extent that it involves risk, the search for innovation and a certain sense of adventure, so to speak, in terms of its production. [...] However, the INCAA insists on ignoring those forms of production and obliges the films that want to enjoy its support to become huge cumbersome things (bodoques) tied to the classic production forms. We believe that these forms are obsolete and that they serve to make films that inherit 
something of that obsolescence. We are interested in vital films, made in a vital way. And vitality is not a coin that runs too generously through the corridors of the INCAA, I can assure you of that. (Llinás and Koza 2009; my translation)

This statement seems to us of utmost importance since it is a reflective moment ending with a revealing and clear position in relation to art. Llinás makes a choice that entails a declarative dimension, since, in one way or another, he affirms that he is committed to a specific task in the name of the common project of art. It seems useful to recall the notion of true choice that has been theorized recently by several theoreticians and philosophers. ${ }^{3}$ The notion of the authentic choice, "where the very core of our being is at stake" (Žižek 2009a, 63), is the fundamental choice which exposes us to a choice that we did not desire and by which "I choose myself." The notion of true choice refers to an existential choice that presupposes the decision of an individual to engage in a project that acquires the status of a symbolic mandate. For Llinás, this begins with a radical non-compromising position of rejecting institutionalized and standardized conceptions of filmmaking, by the very act of refusing blind submission to established procedures. His motivations are explicit: beat the assumptions and preconceptions of what cinema is or how to make films, start with modest means to guarantee full freedom and, above all, avoid annoying interlocutors with economic power who understand nothing about the project or about cinema.

This radical attitude and, of course, the films that he has produced until now place his work in an expanded field, in the field of cinema as art and, at the same time, "marginalizes" his films from the cinema industry and commercial theaters, or at least makes them circulate almost exclusively in the film festival network or academic cinema spaces. Llinás's statement reminds us of another fundamental and radical statement from Jean-Luc Godard. In 1987, when Godard was asked about his contribution as a filmmaker and after the journalist had said to him "you broke everything, you made everything possible," Godard answered with firmness and clarity: "No, we said and we did and we showed that the possible coexisted, that a path can be opened, and I still believe that today" (Godard and Ardisson 1987). ${ }^{4}$ Llinás shares this

3 Butler 2001; Badiou 2008, 2009; Badiou and Žižek 2009; Žižek 2006.

4 Godard later says: "One addresses to the viewer's part - me in particular, now I consciously realize it - who is the director of his own life, telling him perhaps - in a metaphorical way because it is only a set of images - that his own life is possible to live since I managed to make a film" (Godard and Ardisson 1987; my translation). 
vision of cinema, wanting to show that cinema can be something different, and that it can be as accessible as any other artistic discipline.

As Gilles Deleuze $(1953,1)$ says, a choice is always defined according to what it excludes, and Llinás consciously moves away from what is agreed upon as cinema, and turns away from institutional expectations. Instead of doing what he could have done to be accepted and programmed more easily, he made the choice to stand aside. In other words, he made a risky choice, a choice that would expose his film to rejection, to have a hard time finding a market, and so on. Llinás freely assumes and identifies with the task of resisting rules and questioning the dominant forms of cinematic discourse, which comes with accepting risk as part of his research, making "decisions in a situation that remains opaque" (Žižek 20oga, 101). This stance is to bet on the unknown, the new, that which has never been done. It is to throw oneself alone and without any guarantees onto a path that is still to be paved and that very few have dared to tread.

In this way, when Llinás recognizes himself as a filmmaker engaged in a specific artistic project, he simultaneously declares that art is his ultimate frame of reference, and participates as much in the utopian idea of art as in a framework of unwritten, implicit rules that structure and govern the artistic tradition. Thus, the act of engaging authentically indicates the transition from an individual mode of being to one of collective being. Llinás's true choices and renovated film production procedures show a fidelity to the idea of cinema as an art form.

Besides, Llinás believes that cinema envisioned as art is meant to be transformed into something different from what cinema is today: "the democratization of small cameras and editing machines has reached such a point that we can all make films today without dealing with the number of factors with which our predecessors were forced to deal. Within a very short time, cinema should be called different" (Llinás 2014; my translation). Llinás considers that the so-called "professionalization" is a sort of last refuge of aesthetic good sense, a kind of bourgeois common sense of how cinema should be made:

The closer the industry is to a professional organization, the lower and more ignoble the interlocutors are. Think of the conversations, the words that those people use. [...] That is the cinema where film professionals rule and impose a kind of average taste. That has nothing to do with either challenge or risk but with a kind of average good behavior that arbitrates what deserves to be called cinema. Everything that caused problems at some point, and where daring proposals are now being incorporated into 
what is conceived as an official cinema language, where fulfilling the shooting plan or finishing a movie within a fixed time is seen as a value, when this, on the contrary, is actually the great enemy of cinematographic freedom. (Llinás 2014; my translation)

Finally, Llinás affirms that making a movie implies being aware that every film idea sets up its own small ecology that will allow that film to be made. It is a permanent and incessant reworking of the pact. Each film project must state its own production structure. As a filmmaker, one must invent that process and determine its logic and processes:

I refuse to think that the Cinema Business is the only way to think about making movies; I do not want to be a business enterprise that has employees. I refuse to think that this is the only way of generating an economic organization. That the only way to obtain public money is to be a small factory with employees. It's an agreed symbolic notion of a system that I'm not willing to accept. (Llinás 2014; my translation)

\section{Josephine, the Singer or the Mouse Folk}

After watching EXTRAORDINARY STORIES, we stay with a feeling of having experienced something profoundly familiar and, at the same time, profoundly anomalous. It is an unusual film because of its formal originality, the narrative exuberance it displays and its artisanal production methods which, paradoxically, demonstrate a level of professionalism capable of putting the most bureaucratic forms of filmmaking into crisis, and not only in Argentina. Its anomaly, its extreme singularity, is precisely what interests us.

It is the experience of a small difference that ultimately establishes a different relation, a singular relationship with cinema that somehow defers from previous experiences with similar kinds of film objects (a relationship that nevertheless transforms the object into something more than a simple film). This might be attributed to an awareness that postmodern artistic phenomena has, which functions as a language that, by deconstructing the codes that link them with a kind of aesthetic truth, disorganizes the canon, and produces new narratives; a cinema that questions the devices and their productivity, that generates disorganization that points more to intensities than to coherence. In addition to another author (or creator) model, the whole post condition demands another spectator model because the level 
of proposition does not generate coherence (or correctness) in the manner of a master text or a master key; on the contrary, it generates complex or rhizomatic structures of the phenomena.

That is why this film uses the strategic concepts of genre. The novel is the ultimate dialogical genre, a polyphonic device. Bakhtin's notion of dialogisms is attested to here; that means the dialogical relations between content, material and form, where the individual and the social operate simultaneously, take place in the significant interaction with the receiver. On a pragmatic level, the action-reaction of the film on the spectator, allows or demands a much more open possibility of organization, connections, inscriptions, identifications and dialogical processes, through narration seen as series of minor stories and minor becomings.

\section{Conclusion}

To conclude, we would like to convene a singular literary character: Josephine, the Singer or the Mouse Folk from Franz Kafka's last novel, written a few months before his death in 1924. Josephine is a mouse who has a singular voice and when she starts to sing - or, more precisely, to whistle - all those who hear are irresistibly captivated. A crowd formed around her, to the point that some called her the singer, though nothing really justified the term. Whatever Josephine does, what one can be sure of is that it produces a strong effect; her hissing appears both as a power of affirmation and as a tiny difference. As some authors suggest (Dolar 2006, 217-218; Žižek, 2009b, 318-320), through the story of a little mouse, Kafka reflects on the artistic activity, seen as an activity that is both ordinary yet enigmatic. He talks about art as something that is not distinguished in any way from the non-art; and yet something else, elusive or indeterminable, happens all the same. It is therefore an art that is sensitive, which is noticeable, and spreads doubt among those who perceive it (Kafka 1980, 773-774).

The story of Josephine the mouse could be used as a metaphor for Llinás's political position on cinema and filmmaking (as well as Godard's, Eisenstein's and many other artists'), but also for the fragile status of art itself in this postmodern culture or, as Jameson called it, the culture logic of "cynical reason" in late capitalism (Jameson 2011, 74). When Josephine the mouse does her whims, aware of the strong effect of her voice, demanding special privileges (to be exempted from any kind of work in consideration of her singing, to be deprived of her concern for the daily bread and burdens of a mouse struggling for existence, and even - her supreme pretension - to be 
admired and glorified), she asked the impossible because the acknowledgment of her wishes or of her hissing as an art, is at the same time the loss of its enigmatic force, the loss of the minimal difference. It will be reduced to a social function and the unexpected rupture will become the institution, acquiring the power of the law and becoming, at best, a recreation.

\section{References and Further Reading}

Badiou, Alain. 2008. Théorie du sujet. Paris: Seuil.

-. 2009. Second manifeste pour la philosophie. Paris: Fayard.

Badiou, Alain, and Slavoj Žižek. 20og. L'idée du communisme I. London: Lignes.

Butler, Judith. 2001. “In Dialogue: Ernesto Laclau and Judith Butler." Saturday November 17, 2001, 22:55:47 IST.

Dahou, Mohamed, Guy-Ernest Debord, and Gil J. Wolman. (1953) 1996. Potlatch (1954-1957). Paris: Allia.

Deleuze, Gilles. 1953. Empirisme et subjectivité. Paris: Presses universitaires de France.

Dolar, Mladen. 2006. Une voix et rien d'autre. Caen: Nous.

Eisenstein, Sergei M. 1988. “The Dynamic Square." In Selected Works, Volume 1: Writings, 1922- 1934. Bloomington: Indiana University Press.

Godard, Jean-Luc. 1996.JLG/JLG. Autoportrait de décembre. Paris: P.O.L.

Godard, Jean-Luc, and Thierry Ardisson. 1987. "Jean-Luc Godard à propos du cinema." Interview excerpt during the show Midnight BATHS (BAINS DE MINUIT). Ina.fr, December 25, 1987. Video, 12:13. Accessed May 8, 2019. www.ina.fr/video/ Io8046707.

Jameson, Fredric. 1983. The Political Unconscious. Narrative as a Socially Symbolic Act. London: Routledge.

-. 2011. Fictions géopolitiques. Cinéma, capitalisme, postmodernité. Paris: Capricci.

Kafka, Franz. 1980. "Joséphine la cantatrice, ou le peuple des souris." In OEuvres complètes II. Paris: Gallimard.

Llinás, Mariano. 2014. "Filmmaker Talks about Independent Cinema at the Valdivia International Film Festival (FICV).” YouTube video, 1:09:30. March 29, 2016. Accessed May 9, 2019. https://www.youtube.com/watch?v=gaOce2VHCxQ.

Llinás, Mariano, and Roger Alan Koza. 2009. "Las sorprendentes aventuras de Mariano Llinás." Con Los Ojos Abiertos, September 3, 2009. Accessed April 28, 2019. http:// www.conlosojosabiertos.com/las-sorprendentes-aventuras-de-mariano-llinas/.

Schaeffer, Jean-Marie. 1989. Qu'est-ce qu’un genre littéraire? Paris: Seuil.

Žižek, Slavoj. 1999. Le sujet quifâche. Paris: Flammarion.

—. 2006. La parallaxe. Cambridge, MA: MIT Press. 
- 2009a. First as Tragedy, Then as Farce. London and New York: Verso.

—. 2009b. "Remarques pour une définition de la culture communiste." In L'idée du communisme I, edited by Alain Badiou and Slavoj Žižek. Fécamp: Lignes.

\section{About the Author}

Gabriela Rivadeneira Crespo is an artist, researcher and Professor in the Department of Visual Arts at Central University (Quito) and at the Cinema Department at the University of the Arts (Guayaquil) in Equateur. Through a transversal journey between visual art and cinematographic studies, aesthetic theory and contemporary artistic practice, she explores the dialogues between different artistic disciplines, privileging the study of the contextual dimension of art and its conditions of existence outside the traditional art spaces, aiming to clarify its critical and political function. From 1995 to the present she participates in the creation and direction of the Ecuadorian Centre for Contemporary Art (CEAC), focusing her work on research projects and dissemination of contemporary art. 
